\title{
Pattern of Sexual Assault in Gharbia Governorate during the Period between 2011-2014: Retrospective and Cross Section Study
}

\author{
Marwa K. Sherif ${ }^{1}$, Mona M. El-Gohary, Rabab S. El-Kelany and Mona M. Abo El-Noor ${ }^{2}$ \\ ${ }^{1}$ Department of Forensic Institute of Ministry of Justice \\ 2 Department of Forensic Medicine \& Clinical Toxicology, Faculty of Medicine, Tanta university \\ Tanta, Egypt.
}

\begin{abstract}
Background: Sexual assault is a special type of violence with great effects on the victims. In Egypt, there are no accurate statistical data about sexual assault.

Objective: The aim of this work was to study the pattern of sexual assault in Gharbia Governorate, Egypt.

Subjects and methods: This study was conducted in Tanta Department of Forensic Institute of Ministry of Justice, Egypt. It included collection of retrospective data during the period from the start of January 2011 to the end of June 2014.Cross section study of sexual assault cases was also done from the start of July 2014 to the end of December 2014.Complete history taking as well as full general and local examination was done for the studied cases.

Results and conclusion: Total number of sexual assault cases was 229 over the studied period. The median age of victims was 16 years with interquartile range of 10-21 ranging from 3 to 63 years. Most cases $(63.3 \%)$ were less than 18 years, $76 \%$ of the cases were females, and came from urban areas (63.3\%). Unmarried cases constituted 83\%. Rape was the most frequent type of assault (41\%).

Most of the assailants were outside the familial relations to the victims (91.3\%), and a single assailant was responsible in $78.6 \%$ of the cases. The most common type of physical injury was abrasion (46.75\%), whereas the least were bites (1.29\%). Most cases (68.6\%) were examined within 10 days after the assault; hymnal tear was the commonest injury on vulvovaginal examination (88.4\%). Anal examination revealed chronic habit of anal sex in $18.52 \%$ of cases.

The present study concluded that unmarried females under the age of 18years from urban areas constituted the major victims of sexual assault in Gharbia Governorate. Rape was the commonest reported assault in this study. Logistic regression analysis revealed that age, gender and marital status were good predictors of type of sexual assault.

Recommendations: Medico legal examination of sexual assaults should be done as early as possible for the value of collecting evidence. Medical education for the children and their family about methods of protection against sexual assault should be considered.
\end{abstract}

\begin{tabular}{l|l} 
Keywords & sexual assault, Gharbia Governorate, rape, anal sex, logistic regression analysis
\end{tabular}

\section{Introduction}

$\mathrm{S}$ exual assault is a special type of violence with great effects on the victims; it is considered to be a significant global problem, as not only women are the victims but also men and children experienced sexual assault (Jewkes et al., 2002).

Sexual assault is defined as any form of sexual act committed against another person without her or his consent or against individuals who cannot give a valid consent. (Hwa et al., 2010).

Rape is a non-consensual sexual act induced by introduction of a sexual organ into any part of the body of the victim and/or the invasion of the vaginal or anal opening with any object or body part. While sexual abuse is defined as any other non-consensual sexual acts, not including rape or attempted rape (Amenu and Hiko, 2014). Childhood sexual abuse activities may involve physical contact, including penetrative (e.g. rape, buggery or oral sex) or nonpenetrative acts (Hawkins and Domoney, 2012).

Sexual assault has serious effects on public health. Sexual assault has psychological, emotional and physical impacts (Basile et al., 2006). Psychological and emotional problems include anxiety, depression (Choudhary et al., 2008), and post-traumatic stress disorder (Homma et al., 2012; McLean, 2013).

Physical impacts of sexual assaults include sexual and reproductive health problems and drug use (Joskowski and Sanders, 2012). Victims of sexual 
assault are also vulnerable to acquiring sexually transmitted infections (STIs) and experiencing unwanted pregnancies (Allsworth et al., 2009; young et al., 2011; Wadsworth and Records, 2013). The mental health sequelae of sexual violence are serious and long lasting (Das et al., 2013).

The true prevalence of the different forms of sexual violence against women is not well known in Arab world (El-Elemi et al., 2011). In Egypt, there is no precise statistical data on sexual assault. For prevention of sexual violence, it is essential to know the circumstances, the socio demographic data of the victims and the risk factors that affect its occurrence (Mikton, 2010).

So, the aim of this work was to study the pattern of sexual assault in Gharbia Governorate, Egypt, during the period from the start of January 2011 to the end of December 2014.

\section{Subjects and methods}

\section{I- Subjects:}

This study was conducted in Tanta Department of Forensic Institute of Ministry of Justice to analyze cases of sexual assault. It included collection of retrospective data during the period from the start of January 2011 to the end of June 2014.Cross section study of sexual assault cases was also done to cover the period from the start of July 2014 to the end of December 2014. The study included all the sexual assault cases except those who refuse clinical examination.

In the cross section study, an informed consent from victims or their guardians was taken after explaining the nature of examination. For collection of retrospective data, approval of the Head of Tanta Department of Forensic Institute of Ministry of Justice was taken. Confidentiality of records was maintained by keeping the records anonymous.

\section{II- Methods:}

The following items were fulfilled in the studied cases:

1- Complete history taking including personal history and history of the assault including delay time (time between assault and medico legal examination), type of sexual assault, number of assailants and their relation to the victim.

Sexual assault was categorized into: Rape \{forceful vaginal penetration of a woman by a man's penis according to Russell, (1984)\}, attempted rape, anal sex and mixed rape and anal sex.

2- Examination of the subject (mental state, general, and local examination of vulvovaginal and anal regions).

General examination involved examination of the whole body except the local region. It included examination of face, head and neck, upper limbs, chest, abdomen, back and lower limbs. Each region was examined for the presence of bruises, abrasions, lacerations or other injuries.

\section{Local examination:}

- Local examination of vulvo-vaginal region included examination of: mons pubis, labia majora, labia minora, clitoris, posterior fourchette, hymen, vaginal wall and perineum.
- Local examination of the anal region included examination of skin corrugations, anus opening, adjacent area, anal reflex, sphincter tone and tear of anal mucosa (recent - old)

3- Taking swaps from the local area including vaginal and anal swabs

(Infection control measures were considered during taking vaginal and / or anal swabs).

\section{III- Statistical Analysis}

All the tested variables were expressed as numbers and percentages in brackets. Chi square test and multinomial regression analysis tests were used. A $P$ value of $\leq 0.05$ was considered statistically significant. All analyses were performed using SPSS 20.0 for Windows (SPSS Inc., Chicago, Illinois, USA).

\section{Results}

In the present study, sociodemographic data of the studied sexual assault victims demonstrate that the median age of victims was 16 years with interquartile range of 10-21 ranging from 3 to 63 years with a higher significant percentage of victims aged less than 18 years were $(63.3 \%)$. Females were significantly outnumbered males (76\% compared to $24 \%$ respectively). The percentage of cases from urban areas was significantly higher than rural areas $(63.3 \%$ and $36.7 \%$ respectively). Most of the studied cases (83\%) were unmarried as shown in table (1).

Table (2) shows a statistically significant association between age and gender of the studied victims of sexual assault where female and male victims were more subjected to sexual assault in the age group less than 18 (52.9\% and 96.4\% respectively).

Figure (1) demonstrates a higher incidence of sexual assault (31.4\%) in spring whereas the lowest incidence (17\%) was in autumn $\left(\mathrm{X}^{2}=10.28, \quad \mathrm{P}\right.$ value $=0.016)$.

The present study revealed that rape was the most frequent reported type of sexual assault (41\%) followed by anal sex (30.1\%) as illustrated in figure (2). A single assailant was recorded in $78.6 \%$ of the cases as shown in figure (3). Most of the assailants were outside the familial relations to the victims (91.3\%) compared to $8.7 \%$ who were within family relations to the victims as shown in table (3).

As regards delay time between the assault and medic legal examination, figure (4) shows that $68.6 \%$ of the studied victims were examined medico-legally in less than 10 days after the assault, while $31.4 \%$ were examined after that period of time.

Table (4) shows that anal sex was the most encountered assault (40\%) followed by attempted rape (29.7\%) in victims aged less than 18 years. In the age group between 18-40 years, the majority of cases were raped $(65.9 \%)$ followed by anal sex $(13.4 \%)$. In the older age group ( $>40$ years), rape and attempted rape occurred in one case each.

Table (5) shows that the most frequent assault among female victims was rape followed by attempted rape (54\% and 31\% respectively).

All cases of sexual assault were examined mentally and all found mentally competent. During general examination, 152 cases of the studied victims(66.3\%) showed no injuries while77 cases 
(33.62\%) were represented with injuries in the form of abrasions, bruises, cut wounds, burn and bite marks. abrasions and bruises were the most frequently encountered injuries (46.75\% and $41.55 \%$ respectively) while bites represented the least percentage(1.29\%) as shown in table (6).

Local examination of vulvo-vaginal and perineal regions in the studied female victims (160 cases) revealed that $51.25 \%$ of these cases showed no injuries, while $48.75 \%$ showed variable types of injuries. Hymen tears were detected in $88.4 \%$ of cases as shown in table (7). Regarding the incidence of recent and old hymen tear, 24 victims who were examined within 10 days from the assault showed signs of recent torn hymen. Hymnal tear noticed after 10 days was notified as old tear hymen.

Examination of anal region in cases of anal sex and in mixed rape and anal sex revealed signs of chronic habit of anal sex in $18.52 \%$ as shown in table (8). They include weak anal reflex and sphincter tone with flat skin corrugation in addition to wide anal opening and flat anal canal.

Vaginal or anal swabs were taken from victims presented to medico-legal examination within10 days after the assault upon the request of prosecution.Vaginal swabs were taken from 39 cases, positive swabs for presence of semen were found in $71.79 \%$ of the cases. Anal swabs were taken from 9 cases, positive swabs for presence of semen were found in only $66.66 \%$ of cases as shown in table (9).

Table (10) shows that logistic regression analysis was statistically significant, $\chi^{2}=239.873, \mathrm{p}<$ 0.001 . It revealed that age, gender and marital status had a significant contribution $(\mathrm{p}=0.042,<0.001,0.001$ respectively).

Table (11) demonstrates odds ratio of the logistic regression analysis of the effects of age, gender, marital status and residence of the studied victims in predicting the type of sexual assault, increasing age by 1 year was associated with an increased likelihood of being a victim of rape rather than of attempted rape or anal sex but with increasing age the victim was more susceptible to mixed assault rather than rape.

As regards marital status, married individuals compared to unmarried were 29.193 times more likely of being victims of anal sex and they were less likely of having mixed assault or attempted rape (odds ratio 0.677 and 0.354 respectively).Victims from rural regions were associated with an increased likelihood of being victims of rape rather than anal sex $(B=-0.379)$ or mixed assault $(B=-0.004)$ and associated with increased likelihood $(B=0.182)$ of attempted rape. As regards gender, females compared to males were less likely (-18.721) to be victims of anal sex.

Table (1): Chi square goodness of fit test of sociodemographic data of the studied sexual assault victims (N=229)

\begin{tabular}{|l|l|l|l|l|l|}
\hline & & $\mathbf{N}$ & $\mathbf{\%}$ & $\mathbf{X}^{\mathbf{2}}$ & P value \\
\hline Age (years) & Less than 18 & 145 & 63.3 & 134.57 & $<0.001^{*}$ \\
& $18-40$ & 82 & 35.8 & & \\
& More than 40 & 2 & 0.9 & & \\
\hline Gender & Female & 174 & 76 & 61.83 & $<0.001^{*}$ \\
& Male & 55 & 24 & & \\
\hline Residence & Urban & 145 & 63.3 & 16.24 & $<0.001^{*}$ \\
& Rural & 84 & 36.7 & & \\
\hline Marital status & Married & 39 & 17 & 45.10 & $<0.001^{*}$ \\
& Unmarried & 190 & 83 & & \\
\hline
\end{tabular}

* Significant $p<0.05, N$ : number

Table (2): Pearson's chi square test for association between age and gender of the studied victims of sexual assault $(\mathrm{N}=\mathbf{2 2 9})$.

\begin{tabular}{|c|c|c|c|c|c|c|c|}
\hline \multirow{2}{*}{ Age (years) } & \multicolumn{4}{|c|}{ Gender } & \multirow{2}{*}{ Total } & \multirow{2}{*}{$\mathbf{X}^{\mathbf{2}}$} & \multirow{2}{*}{ P value } \\
\cline { 2 - 6 } & Female & \multicolumn{2}{|c|}{ Male } & & & \\
\cline { 2 - 6 } & $\mathbf{N}$ & $\mathbf{\%}$ & $\mathbf{N}$ & $\mathbf{\%}$ & & & \\
\hline Less than 18 & 92 & 52.9 & 53 & 96.4 & 145 & \multirow{2}{*}{34.038} & $<0.001^{*}$ \\
\hline 18-40 & 80 & 46 & 2 & 3.6 & 82 & & \\
\hline More than 40 & 2 & 1.1 & 0 & 0 & 2 & & \\
\hline Total & 174 & 100 & 55 & 100 & 229 & & \\
\hline
\end{tabular}

* Significant $p<0.05, N$ : number 
Table (3): Chi square goodness of fit test of assailant' relation to the studied sexual assault victims $(\mathrm{N}=229)$

\begin{tabular}{|l|l|l|l|l|}
\hline Relation & $\mathbf{N}$ & $\mathbf{\%}$ & $\mathbf{X}^{\mathbf{2}}$ & P value \\
\hline Husband & 8 & 3.5 & 53.66 & $<0.001^{*}$ \\
Father & 3 & 1.3 & & \\
Other relatives & 9 & 3.9 & & \\
Extrafamilial & 209 & 91.3 & & \\
\hline
\end{tabular}

* Significant $p<0.05, N$ : number

Table (4): Pearson's chi square test for association between age and type of studied sexual assault cases $(\mathrm{N}=229)$

\begin{tabular}{|c|c|c|c|c|c|c|c|c|c|c|c|c|}
\hline \multirow[t]{2}{*}{$\begin{array}{l}\text { Age groups } \\
\text { (years) }\end{array}$} & \multicolumn{2}{|c|}{$\begin{array}{l}\text { Rape } \\
\mathrm{N}=94\end{array}$} & \multicolumn{2}{|c|}{$\begin{array}{l}\text { Attempted rape } \\
\mathrm{N}=54\end{array}$} & \multicolumn{2}{|c|}{$\begin{array}{l}\text { Anal sex } \\
\mathrm{N}=69\end{array}$} & \multicolumn{2}{|c|}{$\begin{array}{l}\text { Mixed rape and anal sex } \\
\mathrm{N}=12\end{array}$} & \multicolumn{2}{|c|}{ Total } & \multirow{2}{*}{\begin{tabular}{|l|}
$\mathbf{X}^{2}$ \\
42.278
\end{tabular}} & \multirow{2}{*}{\begin{tabular}{|l|} 
P value \\
$<0.001^{*}$
\end{tabular}} \\
\hline & $\mathrm{N}$ & $\%$ & $\mathrm{~N}$ & $\%$ & $\mathrm{~N}$ & $\%$ & $\mathrm{~N}$ & $\%$ & $\mathrm{~N}$ & $\%$ & & \\
\hline$<18$ & 39 & $26.9 \%$ & 43 & $29.7 \%$ & 58 & $40 \%$ & 5 & $3.4 \%$ & 145 & 100 & & \\
\hline $18-40$ & 54 & 65.9\% & 10 & $12.2 \%$ & 11 & $13.4 \%$ & 7 & $8.5 \%$ & 82 & 100 & & \\
\hline$>40$ & 1 & $50.0 \%$ & 1 & $50.0 \%$ & 0.0 & 0.0 & 0.0 & 0.0 & 2 & 100 & & \\
\hline & & & & & & & & & 229 & 100 & & \\
\hline
\end{tabular}

* Significant $p<0.05, N$ : number

Table (5): Pearson's chi square test for association between gender and type of the studied sexual assault cases (N= 229)

\begin{tabular}{|c|c|c|c|c|c|c|c|c|c|c|c|}
\hline \multirow[t]{2}{*}{ Gender } & \multicolumn{2}{|c|}{$\begin{array}{l}\text { Rape } \\
\mathrm{N}=94\end{array}$} & \multicolumn{2}{|c|}{$\begin{array}{l}\text { Attempted rape } \\
\mathrm{N}=54\end{array}$} & \multicolumn{2}{|c|}{$\begin{array}{l}\text { Anal sex } \\
\mathbf{N}=69\end{array}$} & \multicolumn{2}{|c|}{$\begin{array}{l}\text { Mixed rape and anal sex } \\
\mathrm{N}=12\end{array}$} & \multirow[t]{2}{*}{ Total } & $\mathrm{X}^{2}$ & P value \\
\hline & $\mathrm{N}$ & $\%$ & $\mathrm{~N}$ & $\%$ & $\mathrm{~N}$ & $\%$ & $\mathrm{~N}$ & $\%$ & & \multirow{4}{*}{163.776} & \multirow{4}{*}{$<0.001^{*}$} \\
\hline Female & 94 & 54 & 54 & 31 & 14 & 8 & 12 & 6.9 & 174 & & \\
\hline Male & 0 & 0 & 0 & 0 & 55 & 100 & 0 & 0 & 55 & & \\
\hline & & & & & & & & & $\begin{array}{l}229 \\
100 \%\end{array}$ & & \\
\hline
\end{tabular}

* Significant $p<0.05, \mathrm{~N}$ : number

Table (6): chi square goodness of fit test of types of general injuries in the studied victims of sexual assault (N= 77)

\begin{tabular}{|l|l|l|l|l|}
\hline & N & \% & $\mathbf{X}^{\mathbf{2}}$ & P value \\
\hline Abrasions & 36 & 46.75 & \multirow{2}{*}{548.91} & $<0.001^{*}$ \\
\cline { 1 - 2 } Bruises & 32 & 41.55 & & \\
\cline { 1 - 2 } Abrasions+ bruises & 4 & 5.19 & & \\
\cline { 1 - 2 } Bites & 1 & 1.29 & & \\
\cline { 1 - 2 } Cut wounds & 2 & 2.59 & & \\
\cline { 1 - 2 } Burn & 2 & 2.59 & & \\
\cline { 1 - 2 } Total & 77 & 100 & & \\
\hline
\end{tabular}

* Significant $p<0.05, \mathrm{~N}$ : number

Table (7): chi square goodness of fit of vulvo-vaginal and perineal findings in the examined female cases $(\mathrm{N}=78)$

\begin{tabular}{|l|l|l|l|l|l|}
\hline Site & Type & $\mathbf{N}$ & $\mathbf{\%}$ & $\mathbf{X}^{\mathbf{2}}$ & P value \\
\hline Labia majora & Burn & 1 & $1.3 \%$ & 157.000 & $<0.001^{*}$ \\
& Abrasion & 2 & $2.5 \%$ & & \\
\hline Labia minora & Burn & 1 & $1.3 \%$ & 159.000 & $<0.001^{*}$ \\
\hline Posterior fourchette & Abrasion & 2 & $2.6 \%$ & 158.000 & $<0.001^{*}$ \\
\hline Vaginal wall & Contusion & 2 & $2.6 \%$ & 158.000 & $<0.001^{*}$ \\
\hline Hymen & Tear & 69 & $88.4 \%$ & 69.000 & 0.097 \\
\hline Perineal & Laceration & 1 & $1.3 \%$ & 159.000 & $<0.001^{*}$ \\
\hline
\end{tabular}

* Significant $p<0.05, N$ : number 
Table (8): chi square goodness of fit test of local medico-legal examination of anal region in the studied victims of anal sex and mixed rape and anal sex $(\mathrm{N}=81)$

\begin{tabular}{|l|l|l|l|l|l|}
\hline & & $\mathbf{N}$ & $\mathbf{9}$ & $\mathbf{X}^{\mathbf{2}}$ & P value \\
\hline Anal reflex & Weak & 15 & $18.52 \%$ & 66.000 & $<0.001^{*}$ \\
& Normal & 66 & $81.48 \%$ & & \\
\hline Sphincter tone & Weak & 15 & $18.52 \%$ & 66.000 & $<0.001^{*}$ \\
& Normal & 66 & $81.48 \%$ & & \\
\hline Skin corrugation & Flat & 15 & $18.52 \%$ & 66.000 & $<0.001^{*}$ \\
& Normal & 66 & $81.48 \%$ & & \\
\hline Adjacent skin & Abrasions and bruises & 12 & $17.39 \%$ & 57.000 & $<0.001^{*}$ \\
& Normal & 57 & $82.61 \%$ & & \\
\hline Anal opening & Wide & 15 & $18.52 \%$ & 66.000 & $<0.001^{*}$ \\
& Normal & 66 & $81.48 \%$ & & \\
\hline Anal canal & Flat & 15 & $18.52 \%$ & 66.000 & $<0.001^{*}$ \\
& Normal & 66 & $81.48 \%$ & & \\
\hline Anal mucosa & No tear & 56 & $69.14 \%$ & 54.478 & $<0.001^{*}$ \\
& Old tear & 8 & $9.9 \%$ & & \\
& Recent tear & 17 & $21 \%$ & & \\
\hline
\end{tabular}

* Significant $p<0.05, N$ : number

Table (9): Chi square goodness of fit of vaginal and anal swabs in the studied victims:

\begin{tabular}{|l|l|l|l|l|l|l|l|}
\hline & \multicolumn{2}{|l|}{ Positive } & \multicolumn{2}{l|}{ Negative } & \multirow{2}{*}{ Total } & \multirow{2}{*}{ X2 } & \multirow{2}{*}{ P Value } \\
\cline { 2 - 5 } & $\mathbf{N}$ & $\mathbf{\%}$ & $\mathbf{N}$ & $\mathbf{\%}$ & & & \\
\hline Vaginal swab & 28 & 71.79 & 11 & 28.2 & 39 & 223.66 & $<0.001$ \\
\hline Anal swab & 6 & 66.66 & 3 & 33.33 & 9 & 399.65 & $<0.001$ \\
\hline
\end{tabular}

* Significant $p<0.05, N$ : number

Table (10): Logistic regression analysis of the effects of age, gender, marital status and residence of the studied victims in predicting the type of sexual assault $(\mathrm{N}=229)$

\begin{tabular}{|l|l|l|}
\hline \multirow{2}{*}{ Predictors } & \multicolumn{2}{|c|}{ Likelihood ratio tests } \\
\cline { 2 - 3 } & $\mathbf{X}^{\mathbf{2}}$ & P value \\
\hline Age & 8.220 & $0.042^{*}$ \\
Gender & 62.998 & $<0.001^{*}$ \\
Marital status & 23.315 & $0.001^{*}$ \\
Residence & 0.636 & 0.888 \\
\hline Pseudo R-Squarenagelkerke & 0.711 & \\
\hline Overall accuracy of prediction & $72.1 \%$ \\
\hline
\end{tabular}

Table (11): Odds ratio of logistic regression analysis of the effects of age, gender, marital status and residence of the studied victims in predicting the type of sexual assault $(\mathrm{N}=229)$

\begin{tabular}{|l|l|l|l|l|l|}
\hline \multicolumn{2}{|c|}{ Type of assault } & $\mathbf{B}$ & Std. Error & Sig. & Odds ratio \\
\hline \multirow{4}{*}{ Anal sex } & Age & $\mathbf{- 0 . 1 3 6 -}$ & 0.090 & 0.983 & 0.873 \\
\cline { 2 - 6 } & Marital status (Married) & 3.374 & 1.2 & 0.005 & 29.193 \\
\cline { 2 - 6 } & Residence (Rural) & $\mathbf{- 0 . 3 7 9 -}$ & 0.681 & 0.578 & 0.684 \\
\cline { 2 - 6 } & Gender (Female) & $\mathbf{- 1 8 . 7 2 1 -}$ & 842.578 & 0.982 & $7.406 \mathrm{E}-9$ \\
\hline \multirow{5}{*}{ Mixed rape and anal sex } & Age & $\mathbf{0 . 0 2 0}$ & 0.046 & 0.658 & 1.020 \\
\cline { 2 - 6 } & Marital status (Married) & $\mathbf{- . 3 8 9 -}$ & 0.900 & 0.665 & 0.677 \\
\cline { 2 - 6 } & Residence (Rural) & $\mathbf{- 0 . 0 0 4 -}$ & 0.625 & 0.996 & 0.992 \\
\cline { 2 - 6 } & Gender (Female) & & & & \\
\hline \multirow{5}{*}{ Attempted rape } & Age & $\mathbf{- 0 . 0 9 7 -}$ & 0.047 & 0.038 & 0.907 \\
\cline { 2 - 6 } & Marital status (Married) & $-1.038-$ & 0.896 & 0.247 & 0.354 \\
\cline { 2 - 6 } & Residence (Rural) & $\mathbf{0 . 1 8 2}$ & 0.390 & 0.641 & 1.200 \\
\cline { 2 - 6 } & Gender (Female) & & & & \\
\hline
\end{tabular}

a: reference category is rape, B: co-efficient, Std. Error: standard error 


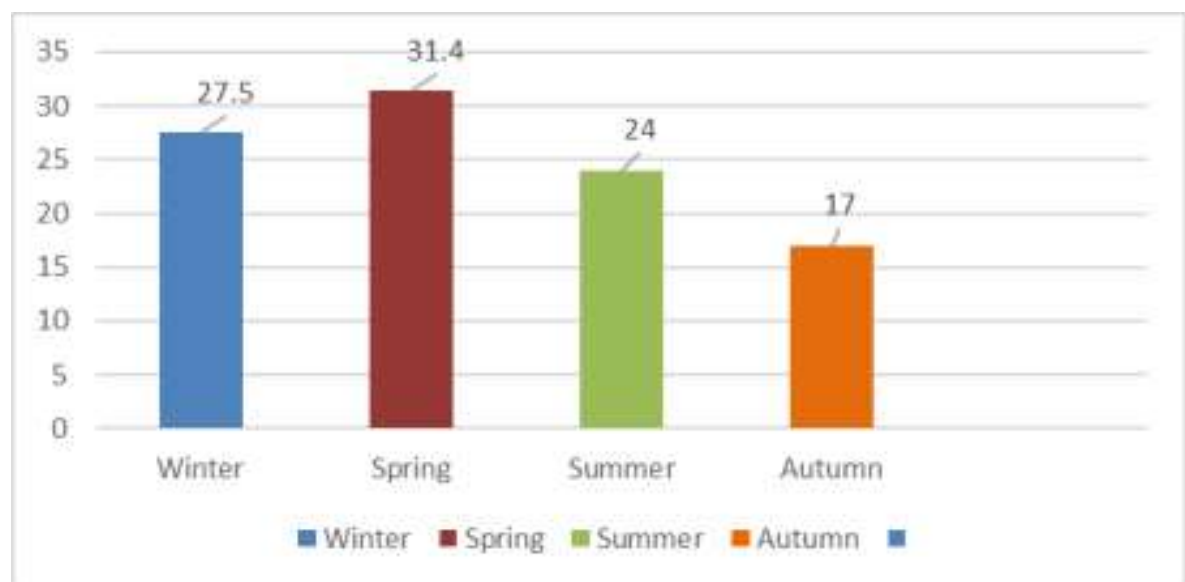

Figure (1): The incidence of sexual assault in the different seasons $(\mathrm{N}=229)$

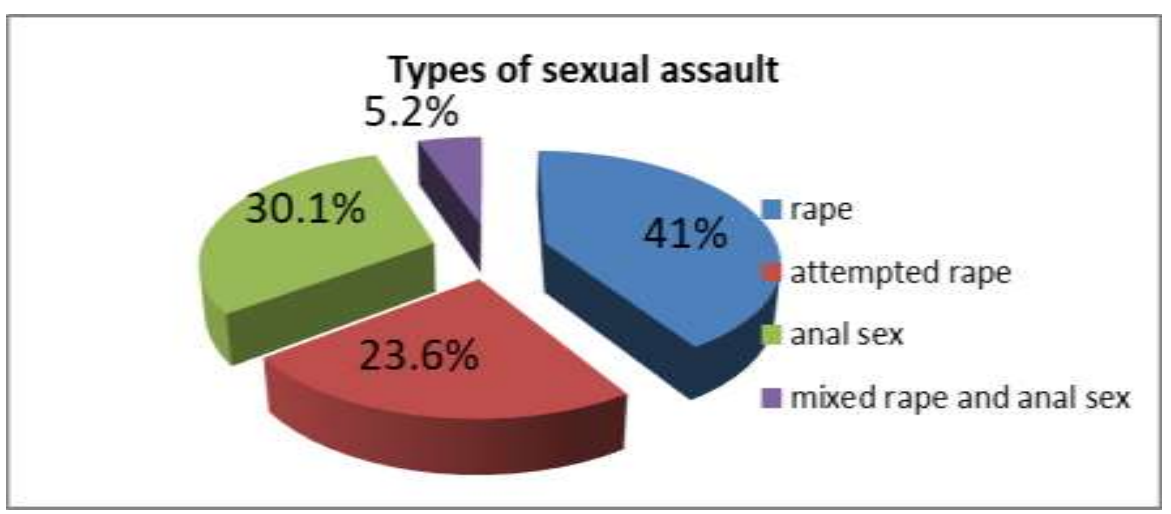

Figure (2): Types of sexual assault in the studied victims $(\mathrm{N}=229)$

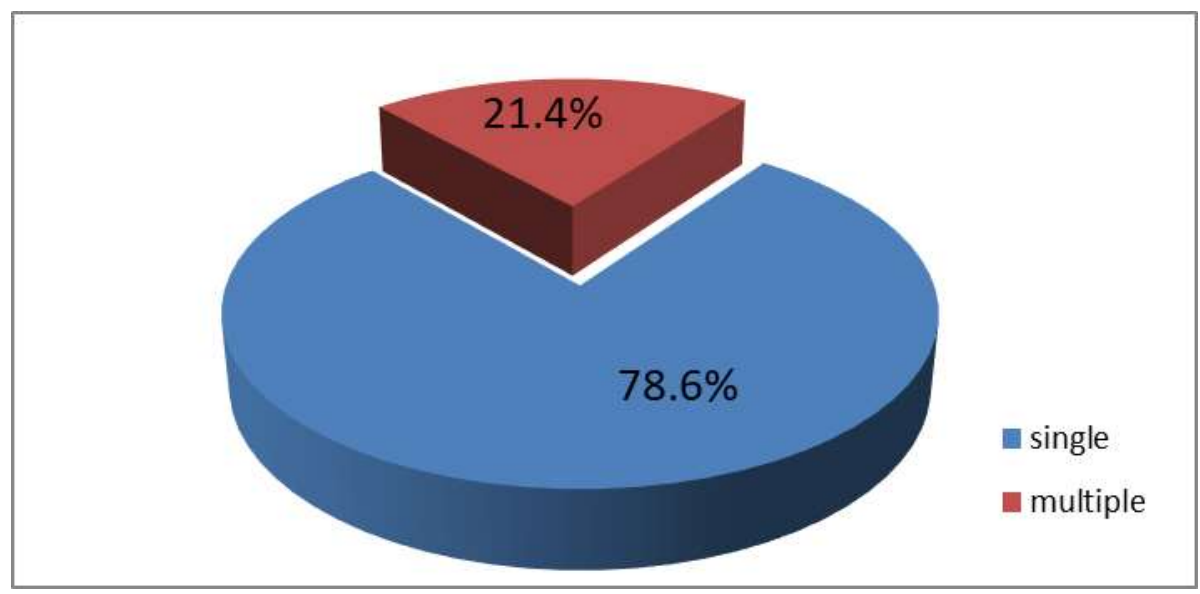

Figure (3): Number of assailants in the studied sexual assault ( $N=229)$ 


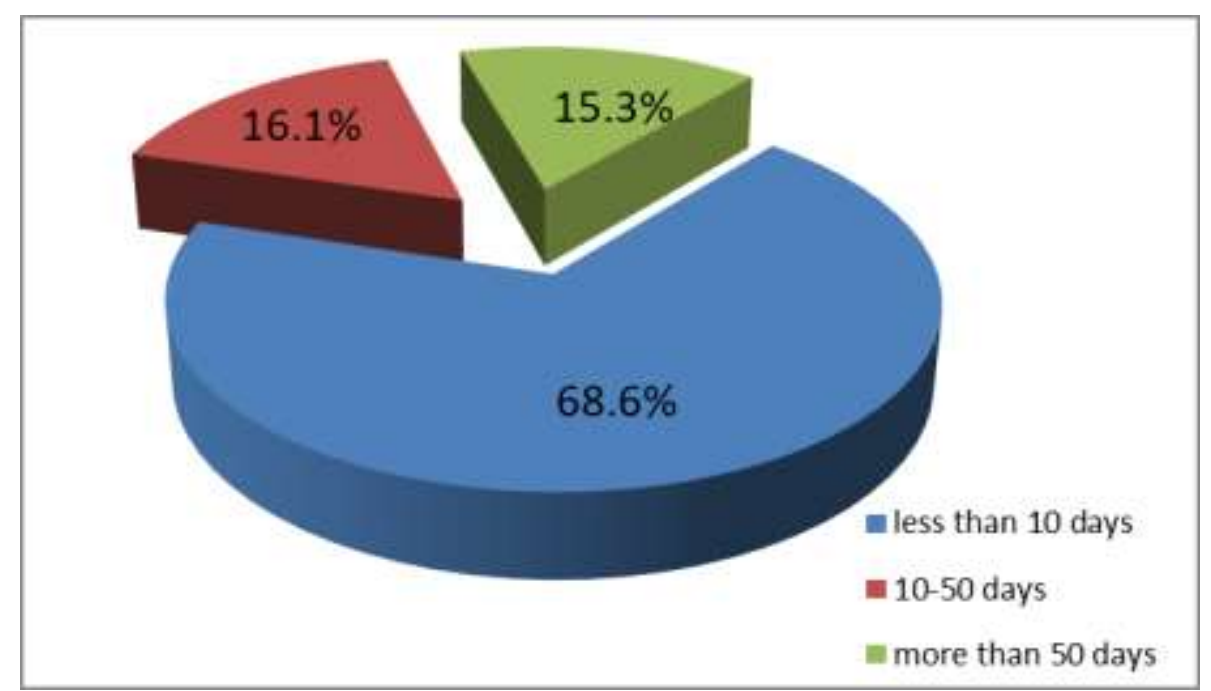

Figure (4): Delay time between the sexual assault and medico-legal examination $(\mathrm{N}=229)$

\section{Discussion}

Sexual violence occurs at all levels of society and in every country of the world. This study was conducted to analyze cases of sexual assault that were examined in Tanta Department of Forensic Institute of Ministry of Justice, Egypt.

Sociodemographic data of the studied sexual assault victims reported that the median age of victims was 16 years with interquartile range of 10-21 (ranged from 3-63 years). This result was in agreement with Karanfil et al., (2013) who stated that the mean age of victims in their study on sexual assault cases examined in Department of Forensic Medicine in Turkey, was 16.78+7.16 years. Moreover, Sharaf El-Din et al., (2015) found the mean (SD) age of victims was 15.2 (6) years ranging from 4 to 40 years in their retrospective study on sexual assault in Qalyubia Governorate, Egypt, in the years from 2009 to 2013.On the other hand, McGregor et al., (2002) revealed that the mean age of sexual assault victims in their study on cases examined in Columbia was 26.7 years.

The highest incidence was observed in ages less than 18 years. Similarly, Das et al., (2013) in their study on sexual assault cases in Kolkata, reported that the most common age group of sexual assault cases ranged between 10-19 years. Sharaf El-Din et al., (2015) reported that 58\% of their cases were in the age group from 12 to 18 years. On the other hand, El-Elemi et al., (2011), in their retrospective study on sexual assault female cases examined in Forensic Medicine Department of the Suez Canal area in Egypt, reported that the highest percentage of victims was between 1828 years old. The variability in the age of sexual assault victims can be attributed to differences in attitude towards sexual act and to differences in cultural characteristic between countries and even between different areas in the same country (Karanfil et al., 2013).

Females in the present study outnumbered males (76\% and $24 \%$ respectively). This result was in accordance with those obtained by Hwa et al., (2010) and Karanfil et al., (2013) who found that females exceed males in their studied victims (93.9\% and $82.7 \%$ respectively). This could be attributed to the attitude of most young females nowadays to spend most of their spare time outdoors exposing themselves to violence. On the other hand, Sivarajasingam et al., (2004), found that male outnumbered female victims in their study (72\% and 28\% respectively).

Most of the studied cases of the present work were from urban areas (63.3\%). This finding agrees with El-Elemi et al., (2011), Das et al., (2013) and Sharaf El-Din et al., (2015)who reported high incidence of sexual assault cases from urban areas (95\%, 66.7\% and $61.5 \%$ respectively). On the other hand, Celbis et al., (2006) reported higher percentage of their studied cases of sexual assault in Turkey from rural areas (76.2\%).

This contrast may be due to the geographical differences between the countries or may be due to ignorance of the rural women in Egypt by the way of reporting the sexual assault, in addition to fear of women of being blamed for the assault (El-Elemi et al., 2011).

Unmarried cases predominated the married ones in our studied victims (83\% and $17 \%$ respectively). These results are in agreement with, ElElemi et al., (2011) and Das et al., (2013) who found that the percentage of unmarried female victims was significantly higher than married ones $(72.5 \%$ and $60.3 \%$ respectively). This could be explained by the precautious attitude of married women against any trivial sexual behavior.

The present study revealed that the majority of female and male victims of sexual assault were less than 18 years (52.9\% and $96.4 \%$ respectively). These results are in agreement with results of Slap et al., (2003) in Nigeria. On contrary to this result, El-Elemi et al., (2011) found that the highest percentage of sexual assault cases was between18 to 28 years (65\%).The increased incidence of sexual assaults among victims less than 18 years could be explained by the attitude of victims of this age to spend long time outdoors, not under the supervision of their families. In addition, they are not oriented to the sexual signals due to their little knowledge about sexual assault (Hilal et al., 2006). 
The highest incidence (31.4\%) of sexual assault cases was in spring season whereas the lowest incidence (17\%) was in autumn. These results are in agreement with Davies et al., (2013) who reported that more cases of sexual assault were in spring (28.2\%) while autumn was the lowest incidence (22.5\%). On the other hand, Sharaf El-Din et al., (2015) found that summer was relatively a vulnerable season for sexual assault (53.1\%). The highest incidence of sexual assault in spring may be due to the pleasant weather that encourages people to spend more time outdoors, resulting in greater chance for personal interaction and increased availability of victims (Sivarajasingam et al., 2004).

Rape (complete vaginal penetration) was the most frequent reported type of sexual assault found in this study (41\%) followed by anal sex (30.1\%). Similarly, EL-Elemi et al., (2011), Karanfil et al., (2013)and Sharaf El-Din et al., (2015) reported rape as the commonest form of sexual violence (35\% , 49.4\% and $48.55 \%$ respectively). This could be explained on the basis that anal sex is not accepted in an oriental society,. In addition, the number of female victims in the present study was more than males.

On contrary, Elgendy and Hassan, (2013) reported anal sex as the most frequent type of sexual assault (52.3\%) followed by incomplete vaginal penetration (32\%), while complete vaginal penetration and mixed vaginal and anal assaults occurred in a small number of cases $(15.7 \%)$. This controversy was attributed to difference in samples. Their study was on children with predominance of males.

The majority of sexual assaults in the present work were perpetrated by single assailant (78.6\%) while multiple assailants were responsible for $21.4 \%$ of the cases. Similarly, Hwa et al., (2010), Karanfil et al., (2013), SudupeMoreno, (2013) and Sharaf El-Din et al., (2015) reported a high percentage of involvement of single assailant in their studies on sexual assault victims (93.9\%, 82.7\%, 86.5\% and 80\%respectively).

The highest percentage of sexual assault cases in the present study was committed by extra familial persons (91.3\%), while other cases were conducted by persons within the family either husband, father, or other members of the family $(3.5,1.3$ or $3.9 \%$ respectively). These results were in agreement with Feldhaus et al., (2000) who found that stranger assaults are more likely than known perpetrators to commit the assaults. Moreover, Sharaf El-Din et al., (2015) reported $16.9 \%$ of the assaulted cases were considered intrafamilial assault, whereas $83.1 \%$ were extra familial. The presence of perpetrators within the family members outside the area of our concepts in Arab countries can be explained by the widespread extended family structure in Egypt and the close relationship between neighbors and people living in the same district.

The current study demonstrated that $68.6 \%$ of the studied victims were examined medico-legally in less than 10 days after the assault, while the rest of the cases were examined after 10 days from the assault. On the other hand, Alempijevic et al., (2007) and Hwa et al., (2010), revealed that most of sexual assault cases were examined within 72 hours from the last assault (84\% and 38.3\% respectively).

The delay in the medico legal examination of the cases in this study up to 10 days after the assault was attributed to non - notification of victims to the police soon after the crime, in addition to the long time consuming steps taken by prosecution before sending the victim for medico legal examination.

The present study revealed that the majority of females were victims of rape followed by attempted rape (54\% and 31\% respectively). It also revealed that most cases under the age of 18 years (40\%) were subjected to anal sex. This could reflect the danger of sexual assaults against male children in our society.

General medico legal examination of victims in the present work revealed absent injuries in $66.37 \%$ of the studied cases. This could be attributed to delayed examination more than 72 hours from the assault, so the positive impacts were hidden. El-Elemi et al., (2011) also explained absent injuries on the basis that the victims were under threat, over powered by assailant, or may be under the effects of drugs. The commonest found injuries were abrasions and contusions (46.75\%, 41.55\% respectively). Alempijevic et al., (2007) and Hwa et al., (2010) found that bruises were the most frequently observed type of injuries (50\% and 86\% respectively). Moreover, Sharaf El-Din et al., (2015) reported abrasions as the commonest injuries in their studied cases $(48.1 \%)$, whereas the least was burn or broken teeth (1.3\% for each).

Local medico legal examination of vulvovaginal and perineal regions including the hymen in the studied female victims (160 cases) revealed no injuries in $51.25 \%$ of the cases, while $48.75 \%$ showed variable types of injuries. Hymen tear was detected in $88.4 \%$ of cases. Sharaf El-Din et al., (2015) recorded lacerations as the commonest local injuries (36.4\%), and the most common location was the hymen (36.4\%). On the other hand, posterior fourchette was the commonest site of genital injury (70\%) reported by Jones et al., (2003).

In the present study, signs of recent hymen tear could be detected within 10 days from the assault. However, victims who were examined after 10 days did not show any sign of recent tear, that is why they were diagnosed of having old torn hymen.

Regarding the local medico legal examination of anal region, the present study showed that victims who had signs of chronic anal sex including weak anal reflex, weak sphincter tone with flat skin corrugation in addition to wide anal opening and flat anal canal were 15 cases (18.52\%), they had shown no signs of general or local injuries.

Most cases of recent tears in anal mucosal were associated with anal skin abrasion and bruises. Anal skin abrasions result from the aggressive 
behavior of the assailant towards the victim on trying to penetrate the anus.

The present study revealed that, vaginal and/or anal swabs were only taken from certain cases within 10 days after the assault upon the prosecution demand. So, only 39 vaginal and 9anal swabs were taken.

It was observed that, $71.79 \%$ of vaginal swabs were positive for the presence of semen, while $66.66 \%$ of anal swabs were positive for semen. Negative vaginal swabs could be attributed to drainage which is the primary cause of loss of seminal fluid constituents followed by dilution with vaginal secretion. Effect of drainage is enhanced by bathing /showering, or ejaculation outside the vagina or the semen may be azospermic, if the diagnosis of semen depends on the present of sperm (Jejeebhoy and Bott, 2005).

In the present study a logistic regression analysis revealed that age, gender and marital status had significant contribution as predictors of being sexually assaulted. Odds ratio of the logistic regression analysis demonstrates that increasing age by 1 year was associated with an increased likelihood of being a victim of rape rather than of attempted rape or anal sex but with increasing age the victim was more susceptible to mixed assault rather than rape. Married individuals compared to unmarried were more likely of being victims of anal sex than mixed assault or attempted rape. Victims from rural regions were associated with an increased likelihood of being victims of rape and attempted rape rather than anal sex or mixed assault. Lastly, females compared to males were less likely to be victims of anal sex.

Comparatively, in the study of Felson and Cundiff (2012), logistic regression analysis revealed that victims at the height of their reproductive potential (ages 15-29 years) were less likely to be raped than older or younger victims. In accordance with the present study, Yuan et al., (2006) reported one of the predictors of sexual assault among women was marital status.

The present study concluded that unmarried females under the age of 18years from urban areas constituted the major victims of sexual assault. Rape was the commonest reported assault. Most assaults involved one assailant who was mostly out of family relations. Most cases revealed no general or local injuries which were related to delay in examination. Logistic regression analysis revealed that age, gender and marital status were good predictors of sexual assault.

\section{Recommendations}

Medico legal examination of sexual assaults should be done as early as possible -even in general hospitals- for the value of collecting evidence. Medical education for the children and their family about methods of protection against sexual assault should be considered. Family counseling centers should be established to support victims and their families in the crises of sexual assault both physically and psychologically. Pregnancy testing should be done for all the female patients of rape or attempt rape.

\section{References}

Alempijevic D, Savic S, Pavlekic S, et al. (2007): Severity of injuries among sexual assault victims. J. Forensic Leg. Med.; 14(5): 266269.

Allsworth JE, Anand M, Redding CA, et al. (2009): Physical and sexual violence and incident sexually transmitted infections. J. Womens Health; 18(4): 529-534.

AmenuD, Hiko D. (2014): Sexual assault: pattern and related complications among cases managed in Jimma University Specialized Hospital. Ethiop. J. Health Sci.; 24(1):3-14.

Basile KC, Black MC, Simon TR, et al. (2006): The association between self- reported lifetime history of forced sexual intercourse and recent health risk behaviors: findings fromthe 2003 national youth risk behavior survey. J. Adolesc. Health; 39:752e1$752 \mathrm{e} 7$.

Celbis O, Gokdog MR, Kaya M, et al. (2006): Review of Forensic assessment of female referrals to the branch of legal medicine,Malatya region, Turky-19962000. J. Clin. Forensic Med.; 13(1) : 21-25.

Choudhary E, Coben JH, Bossarte RM. (2008): Gender differences in the association between sexual violence victimization, health outcomes and risk behaviors. Am. J. Mens. Health; 2: 254-259.

Das I, Chakraborty A, Batabyal S, et al. (2013): A study on the socio-demographic profile of the victims of sex offences attending the Department of Forensic Medicine of a Tertiary Care Institute of Kolkata, West Bengal. IOSR - JDMS.; 11(4):43-47.

Davies EA, Jones AC. (2013): Risk factors in child sexual abuse. J. Forensic Leg. Med.; 20(3):146-150.

El-Elemi AH, Moustafa SM, Hagras AM. (2011): Reported cases of female sexual assault over 5 years period in Suez Canal area, Egypt: demographic study. Egypt. J. Forensic Sci.; 1(3-4):118-123.

Elgendy IS, Hassan NA. (2013): Medico legal study of child sexual abuse in greater Cairo, Egypt, during a 7-year period: 2005-2011. Am. J. Forensic Med. Pathol.; 34(4): 335341.

Feldhaus KM, Houry D, Kaminsky R. (2000): Lifetime sexual assault prevalence rates and reporting practices in an emergency department population. Ann. Emerge. Med.; 36(1): 23-27. 
Felson RB, Cundiff PR (2012): Age and sexual assault during robberies. Evol. Hum. Behav.; 33(1): 10- 16.

Hawkins AP, Domoney C. (2012): Sexual assault and rape. Obstet. Gynaecol. Reprot. Med.; 22(7): 199-204.

Hilal MA, Mohamed SA, Aboul-Hggag KE. (2006): Sexual assault in Sohag Governorate in two years (2002-2003). Sohag Med. J; 10(1): 264-74.

Homma Y, Wang N, Saewyc E, et al. (2012): The relationship between sexual abuse and risky sexual behavior among adolescent boys: A meta-analysis. J. Adolesc. Health; 51(1):1824.

Hwa HL, Chen SC, Wu MZ, et al.(2010): Analysis of cases of sexual assault presenting at a medical center in Taipei. Taiwan J. Obstet. Gynecol.; 49(2):165-169.

Jejeebhoy SJ, Bott S. (2005):Non-consensual sexual experiences of young people in developing countries: An overview. In: Jejeebhoy S. J, Shah I, Thapa S, editors. Sex without consent: Young people in developing countries. London: Zed Books; pp. 3-45.

Jewkes R, Levin J, Mbananga N, et al. (2002): Rape of girls in South Africa. Lancet; 359(9303): 319-320.

Jones JS, Rossman L, Wynn BN, et al. (2003): Comparative analysis of adult versus adolescent sexual assault: epidemiology and patterns of anogenital injury. Acad. Emerg. Med.;10(8): 872-877.

Joskowski KN, Sanders SA. (2012): Health and sexual outcomes of women who have experienced forced or coercive sex. Women Health; 52(2): 101-111

Karanfil R, Keten A, Zeren C, et al. (2013): Evaluation of sexual assaults in Turkey. J. Forensic Leg. Med.; 20(5): 404-407.

Karmakar RN. (2015): Forensic medicine and toxicology: theory, oral and practical Chapter (4): Bimal Kumar. Academic Publishers; $5^{\text {th }}$ edition. p. 142-190.210.
McGregor MJ, Du Dont J, Myhr TL. (2002): Sexual assault forensic medical examination: is evidence related to successful prosecution? Ann. Amerg. Med.; 39(8): 639-647.

McLean I. (2013): The male victim of sexual assault. Best Pract. Res. Clin. Obstet. Gynaecol.; 27: 39-44.

Mikton C. (2010): Preventing intimate partner and sexual violence against women: taking action and generating eviden ce. Inj. Prev.; 16(5): 359-360.

Renner KE. (2001): The civic price of sexual assault and sexual abuse. J. Soc. Distress Homel.; 10:1-4.

Russell DE. (1984): The prevalence and seriousness of incestuous abuse: stepfathers vs. biological fathers. Child Abuse Negl.; 8(1):15-22.

Sivarajasingam V, Corcoran J, Jones D, et al. (2004): Relations between violence, calendar events and ambient conditions. Injury; 35(5):467-73

Slap GB, Lot L, Huang B, Daniyam CA, et al. (2003): Sexual behaviour of adolescents in Nigeria: cross sectional survey of secondary school students. BMJ.; 326(7379):15.

Sudupe Moreno A. (2013): Age differences among victims of sexual assault: a comparison between children, adolescents and adults. J. Forensic Leg. Med.; 20(5): 465-470.

Yuan NP, Koss MP, Polacca M, et al. (2006): Risk factors for physical assault and rape among six Native American tribes. J. Interpers. Violence. 21(12): 1566-1590.

Young MD, Deardorff J, Ozer E, et al. (2011): Sexual abuse in childhood and adolescence and the risk of early pregnancy among women ages 18-22. J. Adolesc. Health; 49: 287-293.

Wadsworth P, Records K. (2013): A review of the health effects of sexual assault on African American women and adolescents. J. Obstet. Gynecol. Neonatal Nurs.; 42(3): 249-273. 


\section{الملخص العربي}

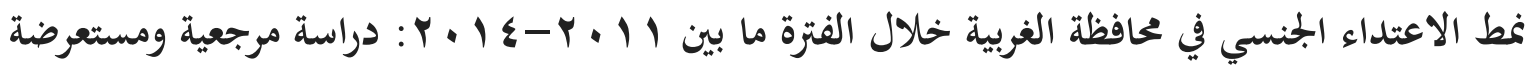

\section{مروة كمال شريفا و منى سيد الجوهري و رباب سيد الكيلاني و منى محمد أبوالنور Y}

المقدمة: يعدالاعتداء الجنسي نوعا خاصا من العنف بين الأفراد الذي يترك آثار نفسية عميقة على الضحايا. وبالنسبة

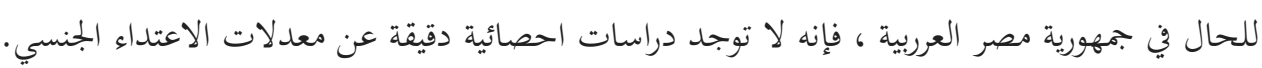

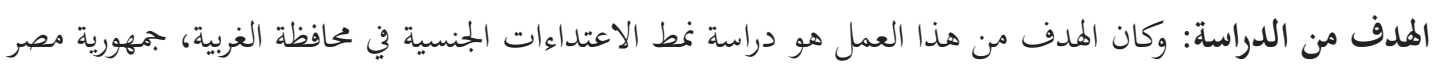

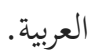

الأشخاص والطرق: وقد أجريت هذه الدراسة في مصلحة الطب الشرعي بدائرة طنطا التابعة لوزارة العدل. وشملت جمع بيانات هذه

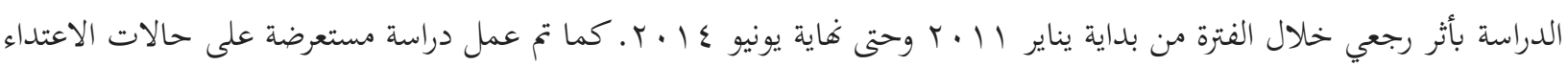

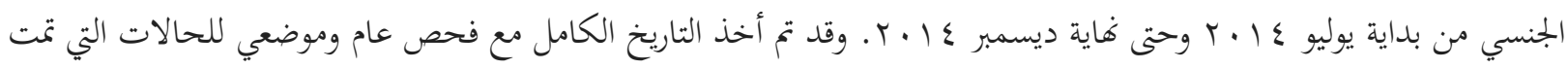
النتائج: بلغ اجمالي عدد حالات الاعتداء الجنسي وج ج خلال فترة الدراسة. وكان متوسط أعمار الضحايا (21-10) 16سنة تتراوح

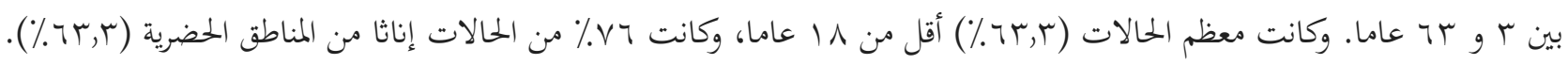

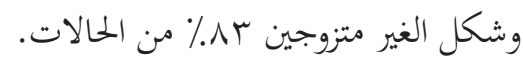

وقد وجد أن الاغتصاب هو النوع الأكثر شيوعا من أنواع الاعتداء الجنسي (اءع).). وكان معظم المعتدين من خارج

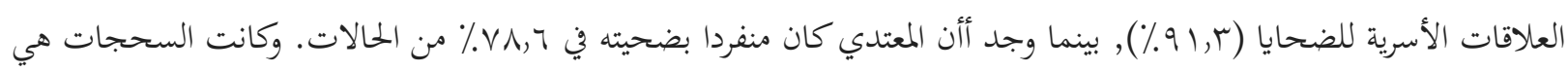

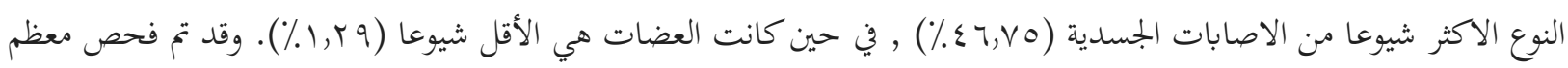

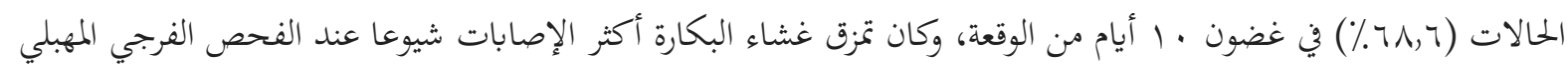

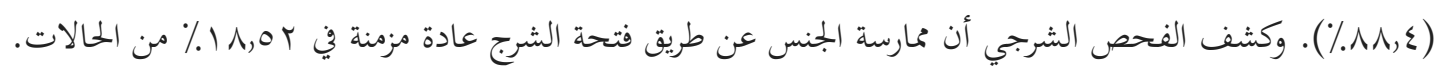

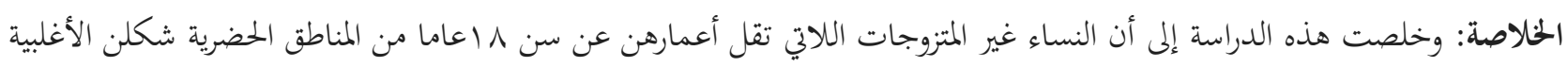

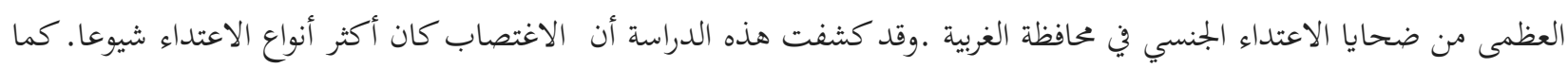

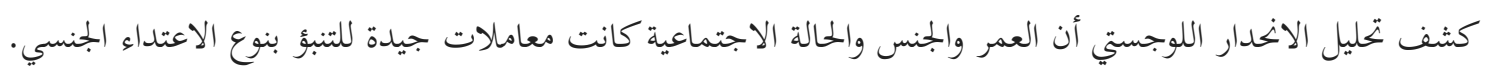

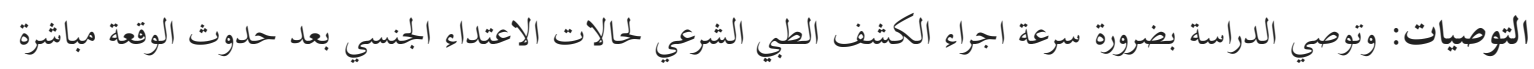

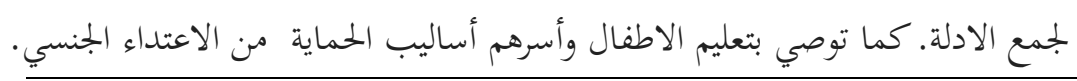

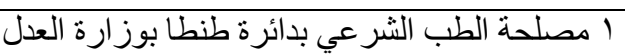

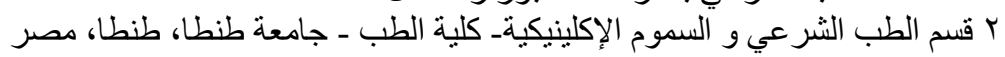

